The Kirkwood set up a two-year pilot project called the Care Coordination team. The team have developed a trusted assessor relationship with the Local Authority and Continuing Healthcare team and work across both services to better service the patients and carers known to the team.

The Care Coordination team offer a telephone-based service with resource to complete home visits if required. The service is available seven days per week. The team have access to both health and social care records. They link in with PCNs, DN and Therapy services, carers' services, benefits advice etc. The team lead on Fast Track funding implementation and care planning and keep abreast of changing COVID19 implications on care and care services.

The team has gone from strength to strength and from a standing start has now doubled the number of referrals it receives (data to be shared for final poster). The service supports patients and carers over time and maintains review contact checking in as and when the patient and carers requires it. The team plan to be developing their capacity to support more people by developing a volunteer role within the team and as part of a wider hospice development of drop-in hubs where they are able to share their health and social care skills and knowledge.

\section{P-224 SOCIAL PRESCRIBING: FACILITATING THE INTEGRATION OF HOSPICE, PRIMARY CARE AND COMMUNITY DEVELOPMENT}

${ }^{1}$ Nikki Archer, ${ }^{2}$ David Atherton, ${ }^{3}$ Sarah Laing, ${ }^{4}$ Garry Jones, ${ }^{4}$ Sandra Payne. ${ }^{1}$ St Giles Hospice, Lichfield, Staffordshire; ${ }^{2}$ East Staffordshire PCN, Staffordshire, UK; ${ }^{3}$ East Staffordshire and Mercian PCN, Staffordshire, UK; ${ }^{4}$ Support Staffordshire, Staffordshire, UK

\subsection{6/spcare-2021-Hospice.239}

Social prescribing is a fundamental aspect of the NHS Long Term Plan. The roll-out of social prescribing is underpinned by the belief that individuals have the capacity to define and solve their own problems and that local communities are rich in social assets, skills and talents which can be tapped into to enhance and improve health and wellbeing. Social Prescribing Link Workers (SPLWs) aim to focus on what matters to each client holistically, looking at social, economic and environmental factors and creating personalised care plans to improve wellbeing linking in to local community resources and assets. This philosophy aligns with both the person centred ethos of hospice care and the Public Health model of Palliative Care.

Aims To adopt a partnership approach to develop and deliver social prescribing through hospice partnerships with local VCSE organisations and local PCNs to develop and deliver social prescribing. Commitment to learning and developing together rather than 'doing' social prescribing through service provision, drawing on the strengths of the local community and the partner organisations.

Actions

- Social prescribers in post fully funded through PCN with commitment for five years - links built with GPs, hospice and other services.

- Partnership approach embedded, service launch in March 2020 - impacted by COVID-19 pandemic, an opportunity and a threat.

\section{Outcomes}

- Social prescribing now embedded in local community and GP practices. Over 500 referrals received in year 1: bereavement, end-of-life care plans, carers support identified as some of the key challenges people face.

- Data and case studies support difference Social Prescribing is making on individual and system perspective.

- NHS Graduate evaluation report completed.

Conclusion Involvement in a partnership approach to social prescribing is supporting the hospice in facilitating a public health model to palliative and end-of-life care being adopted as part of the wider system change.

\section{P-225 ESTABLISHING A PATHWAY OF CARE FOR YOUNG ADULTS WITH LIFE-LIMITING ILLNESS}

Clair Marshall. Nottinghamshire Hospice, Nottingham, UK

\subsection{6/spcare-2021-Hospice.240}

Background Until April 2019, there was no clear pathway in our region for young adults to make the transition from children's hospice care to an adult hospice environment. There is a growing focus on making sure that young people with palliative care needs have a positive experience of transition from child to adult services (Marie Curie Cancer Care \& the Transition Partnership, 2012).

The number of young adults with life-limiting and lifethreatening conditions is much higher than previously thought and numbers are increasing. This increase has come about because children are now living into adulthood due to improvements in medical technology, such as night-time ventilation (Fraser, Miller, Aldridge, et al.,2013).

Aim To establish a clear pathway from children's to adults' hospice services.

Method Using funding awarded by the Albert Hunt grant, we worked alongside our local children's hospice to identify young adults being discharged from their service.

May - July 2019 consultations and co-production with young adults, their families, health professionals, links with partner agencies, television and radio promo. July 2019: first Open Day for consultation with young adults and their families. September 2019: second Open Day to launch the Young Adults' group.

Results Young adults accessing our services: 11 young adults attending the Young Adults' group: 7. In addition to young adults transitioning from children's hospice care, we also support young adults who are newly diagnosed.

Conclusion The Young Adults service is now fully embedded into the core offer of our hospice services.

\section{P-226 ONE STOP DUCHENNE MUSCULAR DYSTROPHY CLINIC; A UNIQUE NHS - YOUNG ADULT HOSPICE COLLABORATION}

Amanda Brain, Carol Ransome. Naomi House and Jacksplace, Winchester, UK

\subsection{6/spcare-2021-Hospice.241}

Background The driver for creating an integrated clinic came from patient feedback highlighting a lack of co-ordinated care across health care services, inappropriately equipped environments and multiple outpatient appointments. Studies have shown 'both quality of life and survival are better in neuromuscular populations treated in multidisciplinary clinics' (Paganoni, Nicholson, Leigh et al., 2017). 
Aims To create a one stop multi-speciality/multidisciplinary Duchenne Muscular Dystrophy (DMD) clinic working across the boundaries of the NHS and non-statutory services. To provide young men with an opportunity to engage with palliative care services as part of their holistic care.

Methods The professionals visited each other's speciality areas/ clinics and commenced a regular meeting to discuss patients in September 2019, the services then commenced a pilot clinic by reorganising existing commitments. The pilot commenced in January 2020 with patient feedback captured post clinic.

Results Despite the challenges of COVID-19, we have successfully run five clinics at Jacksplace to date reviewing 22 patients; 18 in person (four virtually). Each patient has been seen by a neuromuscular consultant, cardiologist, DMD coordinator, physio, transition CNS and palliative medicine associate specialist. The service continues to develop and now offers echocardiograms within the clinic.

The patient feedback is universally in favour of continuing in this format. All commented on the improved facilities, ease of access and that it is 'wonderful to see several professionals on the same day'.

Clinicians highlighted the benefit of this model of care leading to strong communication between professions, saving time and an ability to develop co-ordinated individual plans of care with the young men.

Conclusion Collaboration between professionals and organisations has allowed us to deliver a well co-ordinated, holistic service. It has facilitated the integration of palliative care allowing relationships to build between the multi-professional team and the young men creating a safe environment where conversations about advance care planning can become a normal part of their care.

\section{P-227 LIVING RIGHT UP TO THE END; AN ASSET-BASED COMMUNITY DEVELOPMENT APPROACH TO END-OF- LIFE SUPPORT}

${ }^{1}$ Susan High, ${ }^{2}$ Cormac Russell, ${ }^{1}$ Irene McKie. ${ }^{1}$ Strathcarron Hospice, Denny, UK; ${ }^{2}$ Nurture Development, Dublin, Ireland

10.1136/spcare-2021-Hospice.242

As specialists in palliative care, Strathcarron Hospice understands that with the right support, people with life limiting conditions, their carers and the bereaved can live well right to the end. The New Public Health Model of Palliative Care recognises that dying is not just a medical issue and that social support is often more important than medical. It promotes the importance of social relationships and encourages engagement with communities to identify the people and assets that can provide end of life support.

At Strathcarron Hospice we have adopted an Assets-Based Community Development approach to enable us to understand what communities can do for themselves, what they need a little help with, and what they need salaried professionals to do for them. We recognise that it is only when agencies start organising themselves the way that people organise their lives, instead of expecting people to organise their lives around services and silos, then true partnerships between citizens and institutional systems will emerge.

As a Nurture Development Learning site, we set out to discover the strengths and talents which exist in our local communities. Working in three diverse communities across Forth
Valley, we have created time and a safe space for citizens, associations, local practitioners and helping organisations to learn together how to make invisible assets visible and productive. We have provided opportunities to break down traditional structures that may stifle creativity.

In doing this, we have moved from the traditional model of volunteer Compassionate Neighbours towards communities where everyone's contribution is valued and people feel connected to each other. We aim to create the conditions to support citizens to come together to create a community where people who are aging, dying or grieving can be supported, with institutions (like the hospice) being there to provide specialist help when invited to do so.

\section{P-228 COMPASSIONATE NEIGHBOURS SHARING POWER AND RESOURCES WITH COMMUNITIES TO DRIVE BETTER END-OF-LIFE CARE}

${ }^{1}$ Kate Heaps, ${ }^{2}$ Nicki Shaw, ${ }^{3}$ Heather Richardson, ${ }^{1} J o n$ Devlin. ${ }^{1}$ Greenwich and Bexley Community Hospice, London, UK; ${ }^{2}$ Princess Alice Hospice, London, UK; ${ }^{3}$ St Christopher's Hospice, London, UK

\subsection{6/spcare-2021-Hospice.243}

Background Hospices are experts in end-of-life care, embedded in communities and ideally placed to share our expertise. This is the aim of Compassionate Neighbours (CNs), a well-established programme, growing across London and the South East of England.

Aims The programme aims to:

- Redefine the relationship between hospices and people suffering from social isolation/disconnection.

- Co-design and deliver support for people bereaved or coming to the end of their lives.

- Develop authentic and reciprocal relationships which penetrate the whole community.

Method

- Hospices invite people to train as CNs.

- Trained CNs are connected with community members who seek a new relationship to help them cope with loneliness arising from serious illness/end-of-life care challenges.

- CNs have access to regular support and advice from the hospice/network of CNs.

- The programme was evaluated by independent researchers and studied as part of a completed $\mathrm{PhD}$ project.

- Evaluation findings and data on demography and reach will be shared, alongside case-studies to illustrate impact.

Results

- Positive change in the wellbeing of participants, reducing loneliness, increasing connectivity and ascribing meaning and value to life.

- New social capital between the hospice and communities with power differentials challenged, participants enjoy greater agency and citizens feel increased ownership of end-of-life issues and the hospice.

- Increases in recruiting and matching CNs during COVID-19. There are now over 1,800 CNs.

Conclusions There is growing acknowledgement of morbidity and mortality related to loneliness and social isolation. CNs provide relationships and connectivity for isolated people. CNs increase their own networks, skills and death literacy. 